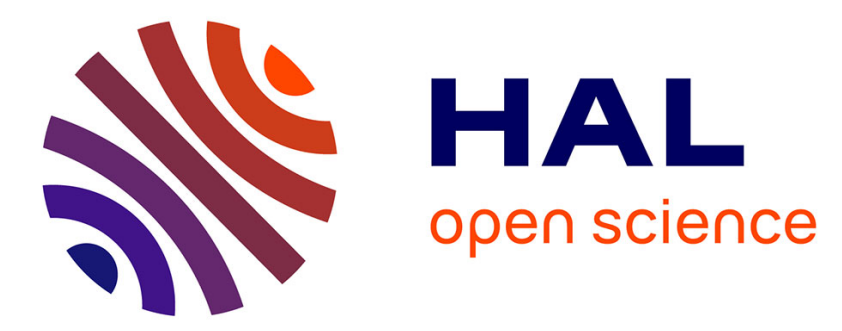

\title{
Helical Bisphosphinites in Asymmetric Tsuji-Trost Allylation: a Remarkable P:Pd Ratio Effect
}

Caleb Medena, Corinne Aubert, Etienne Derat, Louis Fensterbank, Geoffrey

Gontard, Omar Khaled, Cyril Ollivier, Nicolas Vanthuyne, Marc Petit, Marion Barbazanges

\section{To cite this version:}

Caleb Medena, Corinne Aubert, Etienne Derat, Louis Fensterbank, Geoffrey Gontard, et al.. Helical Bisphosphinites in Asymmetric Tsuji-Trost Allylation: a Remarkable P:Pd Ratio Effect. ChemCatChem, 2021, 13 (21), pp.4543-4548. 10.1002/cctc.202101072 . hal-03420672

\section{HAL Id: hal-03420672 https://hal.science/hal-03420672}

Submitted on 9 Nov 2021

HAL is a multi-disciplinary open access archive for the deposit and dissemination of scientific research documents, whether they are published or not. The documents may come from teaching and research institutions in France or abroad, or from public or private research centers.
L'archive ouverte pluridisciplinaire $\mathbf{H A L}$, est destinée au dépôt et à la diffusion de documents scientifiques de niveau recherche, publiés ou non, émanant des établissements d'enseignement et de recherche français ou étrangers, des laboratoires publics ou privés. 


\section{ChemCatChem}

\section{Helical bisphosphinite in asymmetric Tsuji-Trost allylation: a remarkable P/Pd ratio effect \\ --Manuscript Draft--}

\begin{tabular}{|c|c|}
\hline Manuscript Number: & \\
\hline Corresponding Author: & $\begin{array}{l}\text { Marion Barbazanges } \\
\text { Sorbonne Universite } \\
\text { Paris, FRANCE }\end{array}$ \\
\hline Corresponding Author E-Mail: & marion.barbazanges@sorbonne-universite.fr \\
\hline & Caleb Medena \\
\hline & Corinne Aubert \\
\hline & Etienne Derat \\
\hline & Cyril Ollivier \\
\hline & Nicolas Vanthuyne \\
\hline & Marc Petit \\
\hline Keywords: & helicene * phosphinite * homogeneous catalysis * chirality * Tsuji-Trost allylation \\
\hline \multirow[t]{3}{*}{ Suggested Reviewers: } & $\begin{array}{l}\text { Irena Stara } \\
\text { professeur, IOCB CAS: Ustav organicke chemie a biochemie Akademie ved Ceske } \\
\text { republiky } \\
\text { irena.stara@uochb.cas.cz } \\
\text { Expert in helicene chemistry }\end{array}$ \\
\hline & $\begin{array}{l}\text { Giovanni Maestri } \\
\text { Universita degli Studi di Parma } \\
\text { giovanni.maestri@unipr.it } \\
\text { Expert in palladium chemistry and DFT calculation }\end{array}$ \\
\hline & $\begin{array}{l}\text { King Kuok (Mimi) Hii } \\
\text { Imperial College London } \\
\text { mimi.hii@imperial.ac.uk } \\
\text { Expert in enantioselective catalysis - reported a similar ligand-to-metal ratio effect in } \\
\text { tsuji-trost allylation }\end{array}$ \\
\hline \multicolumn{2}{|l|}{ Opposed Reviewers: } \\
\hline Abstract: & $\begin{array}{l}\text { This article discloses a study on a chiral bis-phosphorylated-helical ligand in the } \\
\text { palladium-catalyzed Tsuji-Trost allylation. The use of } 2,15 \text {-bisphosphinite[6]helicenes } \\
\text { allowed to evidence a remarkable ligand effect, in which the }(R) \text { and }(S) \text { isomeric } \\
\text { products can be selectively formed as a direct function of the amount of ligand }\end{array}$ \\
\hline
\end{tabular}


introduced. Study of the organometallic species involved through 31P NMR analysis of a model complex and X-Ray diffraction analysis together with DFT calculations shed light on this phenomenon.

\section{Author Comments:}

Section/Category:

Additional Information:

Question

\section{Response}

Do you agree to comply with the legal and Yes ethical responsibilities outlined in the journal's Notice to Authors?

Has a previous version of this manuscript No been submitted to this journal?

Is this manuscript, or part of it, currently No under consideration elsewhere?

Is this manuscript, or part of it, published, No posted, or in press? This includes content posted on preprint servers (preprint guidelines) or published as part of a thesis.

Please provide us with information about the history of your manuscript, including previous submissions, transfers, or prior versions:

Does the research described in this No

manuscript include animal experiments or human subjects or tissue samples from human subjects?

Do you or any of your co-authors have a conflict of interest to declare?

No
Dear Editor,

This cover letter attends the submission of the article entitled "Helical bisphosphinite in asymmetric Tsuji-Trost allylation: a remarkable P/Pd ratio effect". It discloses a comprehensive study on a chiral bis-phosphorylated helical ligand in palladiumcatalyzed Tsuji-Trost allylation. We found that, unlike the other carbohelicenes evaluated in the literature, the use of 2,15-bisphosphinite[6]helicenes led to a remarkable ligand effect. Indeed, the (R) and (S) isomeric products can be formed selectively as a direct function of the amount of ligand introduced. The study of the organometallic species involved through 31P NMR analysis of a model complex and XRay diffraction analysis as well as DFT calculations on reactive intermediates shed light on this phenomenon. Moreover, these results highlight the criticalimportance of screening the ligand-to-metal ratio when evaluating new ligands.

We therefore this article is of great interest to those working in the field of helicene chemistry, but also to the wider ChemCatChem community. 


\title{
Helical bisphosphinite in asymmetric Tsuji-Trost allylation: a remarkable $\mathrm{P} / \mathrm{Pd}$ ratio effect.
}

\author{
Caleb Medena, ${ }^{[a]}$ Corinne Aubert, ${ }^{[a]}$ Etienne Derat, ${ }^{\left[{ }^{[a]}\right.}$ Louis Fensterbank,,${ }^{[a]}$ Geoffrey Gontard, ${ }^{[a]}$ Omar \\ Khaled, ${ }^{[a]}$ Cyril Ollivier, ${ }^{[a]}$ Nicolas Vanthuyne, ${ }^{[b]}$ Marc Petit, ${ }^{[a]}$ Marion Barbazanges ${ }^{\star[a]}$
}

Dedication ((optional))

[a] C. Medena, Dr. C. Aubert, Dr. E. Derat, Pr. L. Fensterbank, G. Gontard, O. Khaled, Dr. C. Ollivier, Dr. M. Petit, and Dr. M. Barbazanges Sorbonne Université, Faculté des Sciences et Ingénierie, CNRS, Institut Parisien de Chimie Moléculaire (UMR CNRS 8232), 4 place Jussieu, 75252 Paris Cedex 05 (France).

E-mail: marion.barbazanges@sorbonne-universite.fr

[b] Dr. N. Vanthuyne, Aix Marseille Univ CNRS, Centrale Marseille, iSm2, Marseille (France)

Supporting information for this article is given via a link at the end of the document.((Please delete this text if not appropriate))

Abstract: This article discloses a study on a chiral bisphosphorylated-helical ligand in the palladium-catalyzed Tsuji-Trost allylation. The use of 2,15-bisphosphinite[6]helicenes allowed to evidence a remarkable ligand effect, in which the $(R)$ and $(S)$ isomeric products can be selectively formed as a direct function of the amount of ligand introduced. Study of the organometallic species involved through ${ }^{31} \mathrm{P}$ NMR analysis of a model complex and X-Ray diffraction analysis together with DFT calculations shed light on this phenomenon.

\section{Introduction}

Helicenes are organic aromatic compounds formed of several ortho-fused rings which naturally adopt a helical configuration and possess high chiroptical properties. They have already found broad applications in optics, electronics and biology as well as in organic and supramolecular chemistry.[1] Nevertheless, application of these scaffolds as chiral ligands in organometallic catalysis still remains a challenge to tackle and only a few examples are disclosed in the literature.

The first use of a chiral helical ligand in asymmetric organometallic catalysis was reported by Reetz and co-workers in 1997 who designed a chiral 2,15-bis(diphenylphoshino) [6] helicene bisphosphane 1a (Figure 1).[2] By using this chiral ligand in rhodium-catalyzed itaconic acid ester hydrogenation reaction, enantiomeric excesses (ee's) were nonetheless limited (39\%). When used in 2000 in palladium catalyzed Tsuji-Trost allylation, higher ee's of $84-88 \%$ were obtained.[3] To improve these first ee's and to enlarge the catalytic scope, the research groups focused on helicene structural modification. If the synthesis of Forni's and Licandro's tetrathiaheterohelicene bisphosphane 1b led to similar ee's in hydrogenations,[4] Eilbracht, Starý and Stará disclosed the synthesis and the use of phosphite-substituted [6]pseudohelicenes such as 1c, possessing both helical and central chirality.[5] This ligand, substituted in position 2, led to allylic amination product in high ee (up to $94 \%$ ee). In 2014, Marinetti, Voituriez and co-workers moved a step forward in helicene-driven enantioselective organometallic catalysis by synthesizing helical phosphindoles $\mathbf{1 d}$, embedding the phosphorus atom in the helical ring.[6] The corresponding cationic gold(I) complex was successfully used in enantioselective 1,6-enyne cycloisomerization (up to $86 \%$ ee's) as well as allene-ene hydroxycyclization (up to $92 \%$ ee's). In 2016, Suemune, Usui and co-workers described the use of a 1-phosphane-[5]-helicene 1e as chiral ligand. By substituting the helicene in the position 1 , the reaction site is set as close as possible from the chiral helical cavity. Hence, they performed highly enantioselective palladium-catalyzed Tsuji-Trost allylation as well as Suzuki-Miyaura cross-coupling.[7] Noteworthy, the crystallized [Pd]helicene complex discloses a Pd-arene $\pi$-stacking interaction, blocking the conformation and thus rationalizing the high selectivity observed. Shortly after, Tsujihara, Kawano and co-workers reported the use of a 1-phosphinite-[6]helicene 1f, disclosing a similar reactivity in Tsuji-Trost allylation (Figure 1).[8]

Figure 1. Helical phosphorus ligands in organometallic catalysis.

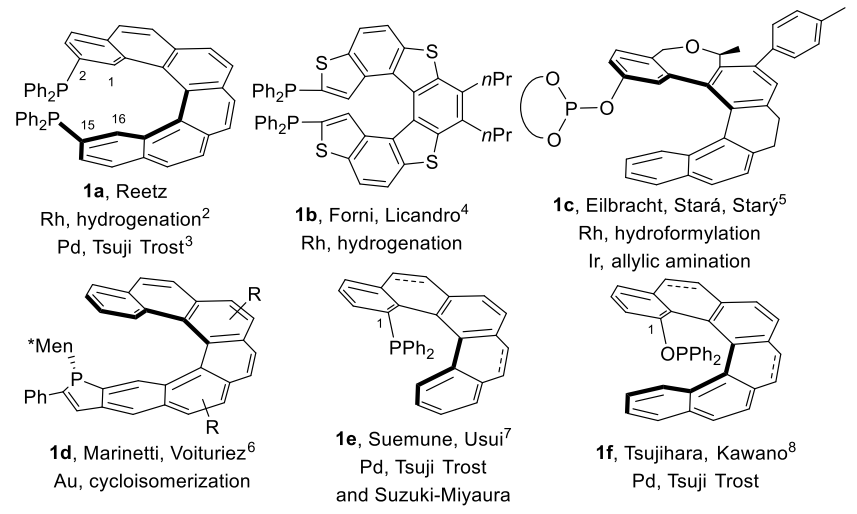

We reported in 2019 the synthesis of chiral 2,15-bisphosphinite [6] helicene $\mathbf{1 g}$ (Scheme 1) and its use in gold-cycloisomerization reactions of 1,6-enynes. While the catalytic activity proved to be satisfying as cycloisomerization occurred, low ee's up to $6 \%$ were obtained. No significant improvement was observed in a methoxycyclization reaction as the product was isolated in $12 \%$ 
ee in the best conditions. We linked these very low enantiomeric excesses to the linear coordination of gold(I) together with the absence of aurophilic interaction in the involved catalyst.[9] We thus envisaged to move from linear gold $(I)$ to a square planar complex, in order to maximise the steric hindrance around the metal and thus optimize the enantioinduction. Moreover, in order to increase the flexibility of the helicene and to tune the electronics of the template, we completed the study by synthesizing nonrearomatized helix $\mathbf{1 h}$ as well as an oxygenated analog $\mathbf{1 i}$ (Scheme 1).

Scheme 1. Synthetic strategy

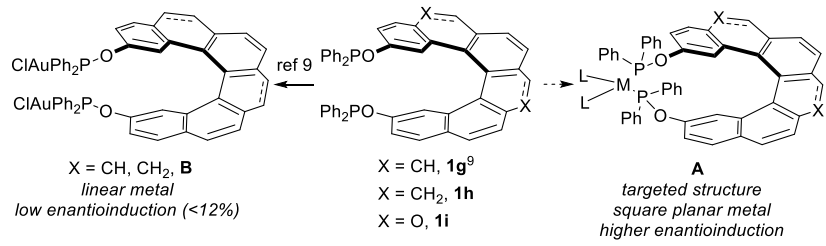

\section{Results and Discussion}

\section{Ligand synthesis}

If formation of saturated bismethoxyhelicene $6 \mathrm{~h}$ (Scheme 2) directly arose from literature procedures, ${ }^{[9],[10]}$ heterohelicene $6 \mathbf{i}$ was synthesized by a Sonogashira cross-coupling between alkyne $\mathbf{2} \mathbf{i}$ and iodide $\mathbf{3 i}$. Cleavage of both methoxymethyl (MOM) protecting groups in $\mathbf{4 i}$ revealed to be tricky as the free phenol function tends to cyclize and yield the corresponding benzofuran. Therefore a one-pot deprotection/alkylation sequence was required to get to the corresponding propargylic ether $5 \mathbf{i}$. Cobaltcatalyzed [2+2+2] cycloaddition led then efficiently to the desired helixe $6 \mathbf{i}$. Whereas methoxy cleavage in $\mathbf{6} \mathbf{h}$ by treatment with $\mathrm{BBr}_{3}$ led to saturated helixol $\mathbf{7 h}$ as expected, partial cleavage of the benzylic ethers in 7i was observed and acyclic adducts were isolated.[11] Gratifyingly, subsequent treatment under basic conditions $\left(\mathrm{K}_{2} \mathrm{CO}_{3}\right.$, acetone, reflux) led to the heterohelixol of interest 7i. We developed preparative chiral HPLC methods that led to excellent separation of both enantiomers of helixols $7 \mathrm{~h}$ and 7i (ee>99\%, see supporting information).[12] Subsequent phosphorylation was achieved by treatment with $\mathrm{PPh}_{2} \mathrm{Cl}$ in the presence of triethylamine as the base (Scheme 2).

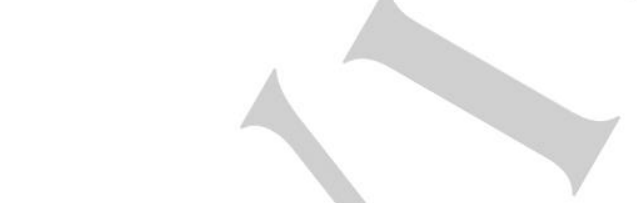

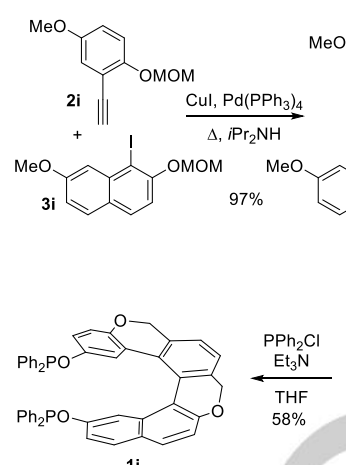

1i

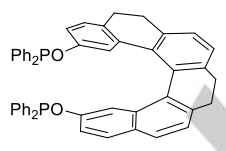

$1 \mathrm{~h}$
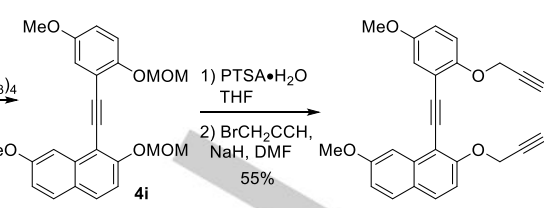

CpCo(CO)dmfu ${ }^{\mathbf{5 i}}$ micro-wave

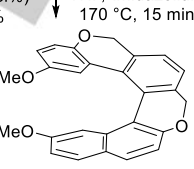

$( \pm)-6$
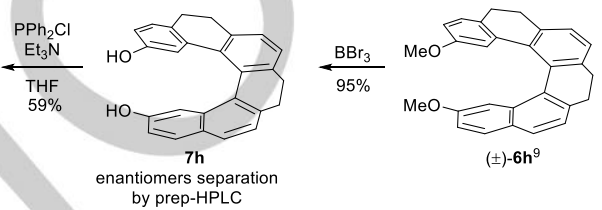

$( \pm)-6 h^{9}$

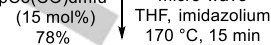

enantiomers separa
by prep-HPLC

Scheme 2. Synthesis of bisphosphinites $\mathbf{1 h}$ et $\mathbf{1 i}$ (dmfu: dimethylfumarate)

Saturated helixol $( \pm)-7 \mathrm{~h}$ was crystallized through slow $\mathrm{CD}_{2} \mathrm{Cl}_{2}$ evaporation (Figure 2). X-ray analysis revealed that it has an inner pitch elevation (C1 $\cdots C$ C16 distance) of 3.065(5) $\AA$ and an oxygenoxygen distance of $5.777(4) \AA$. The terminal inner helix torsion angles show an unequal opening at $3.3(6)^{\circ}$ and $26.5(5)^{\circ}$. The interplanar angle of the two terminal rings is $56.4(3)^{\circ}$.
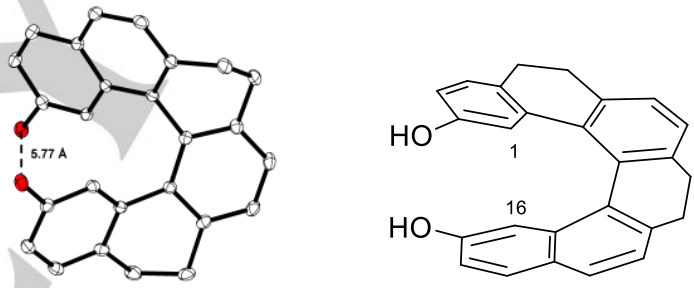

Figure 2. X-ray of $( \pm)$-7h with thermal ellipsoids at $30 \%$ probability. Hydrogen atoms and solvent omitted for clarity

Optical activities of the helixols $\mathbf{7 h}$ and $\mathbf{7 i}$ were measured by circular dichroism spectroscopy. Tetrahydrohelicene $7 \mathrm{~h}$ and oxahelicene 7i exhibited a similar optical rotation of $[\alpha]_{D}=+1010$ (c $0.05 \mathrm{mg} / \mathrm{mL}, \mathrm{CHCl}_{3}$ ) [-1005 (c $\left.\left.0.05 \mathrm{mg} / \mathrm{mL}, \mathrm{CHCl}_{3}\right)\right]$ and +900 (c $0.05 \mathrm{mg} / \mathrm{mL}, \mathrm{CHCl}_{3}$ ) [-990 (c $\left.\left.0.05 \mathrm{mg} / \mathrm{mL}, \mathrm{CHCl}_{3}\right)\right]$, respectively, for the $(P)$ enantiomer $[(M)$ enantiomer]. CD spectrum of tetrahydrohelicene $(P)-7 \mathrm{~h}$ disclosed a broad negative band around $(-) 228 \mathrm{~nm}$, a small positive band at $(+) 251 \mathrm{~nm}$ and an intense one at $(+) 295 \mathrm{~nm}$, accompanied with a shoulder at $(+) 350$ $\mathrm{nm}$ (Figure 3, dotted line). CD spectrum of $(P)-7 \mathbf{i}$ is very similar to tetrahydrohelicene one, with a broad negative band at $(-) 230 \mathrm{~nm}$ and two positives bands at $(+) 250 \mathrm{~nm}$ and $(+) 292 \mathrm{~nm}$, although the band at $(+) 292 \mathrm{~nm}$ is attenuated (Figure 3 , plain line). 
Figure 3. Helixols $\mathbf{7 h}$ and $\mathbf{7 i}$ electronic circular dichroism spectra in $\mathrm{CH}_{2} \mathrm{Cl}_{2}$

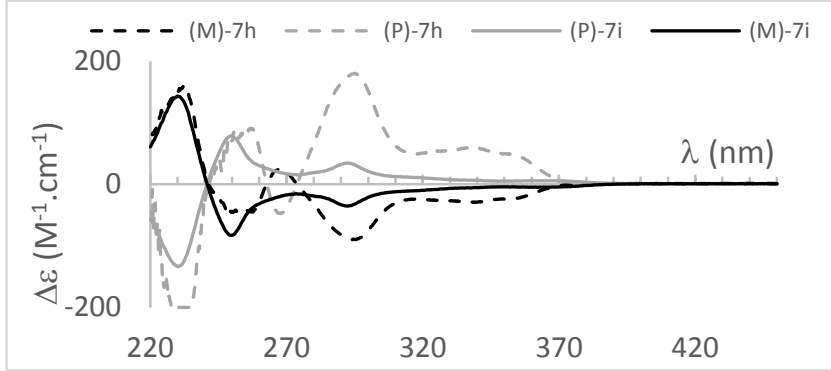

\section{Chiral HELIXOL derivatives in Tsuji-Trost reaction}

These ligands were then evaluated in enantioselective catalysis. We selected palladium(II) to fit in a square planar complex, and Tsuji-Trost allylation[13],[14] as the catalytic reaction for the sake of comparison with the previously reported results where carbohelicenes were used as ligands. These previously published results are reported in Table 1, entries 1-4.

First evaluation and optimization of the reaction conditions were conducted with fully aromatized bisphosphinite $(M)-\mathbf{1 g}$. When no ligand is introduced, no conversion of the starting material was observed (entry 5).[15] Surprisingly, when 2,15-bisphosphinite [6] helicene $(M)-\mathbf{~ g}$ is introduced in classical conditions, in a phosphorus atom : palladium atom ratio ( $\mathrm{P}: \mathrm{Pd})$ of 2:1, nonreproducible results were obtained as both enantiomers were obtained in turn, albeit in very low enantiomeric excesses ranging from $25 \%(S)$ to $16 \%(R)$ (entry 6 ).

We thus played around the phosphorus/palladium ratio and doubled the amount of ligand introduced. In this case, the selectivity is recovered as the $(S)$ enantiomer is obtained in a reproducible fashion with an excess of $49 \%$ (entry 7 ). We then tested the reaction using this time an increasing amount of palladium (entries 8 to 12). Surprisingly, under all these conditions was observed an inversion of selectivity. Indeed, the use of $4 \%$ mol $(P: P d=1.2: 1$, entry 8$)$ then $5 \%$ mol $(P: P d=1: 1$, entry 9$)$ of the palladium complex leads to the predominant formation of the $(R)$ enantiomer in $41 \%$ and $50 \%$ ee, respectively. The enantiomeric excess peaks at $62 \%$ when we use $8 \% \mathrm{~mol}$ $(P: P d=0.6: 1$, entry 11$)$ of the palladium complex.

The influence of temperature was then evaluated. When the reaction was carried out at $0^{\circ} \mathrm{C}$, no conversion was observed (entry 13). At reflux, the desired product was obtained with $52 \%$ enantiomeric excess, ie a slight decrease in the latter (entry 14). We then assessed the influence of the helical skeleton. When oxahelicene $(M)$-1i was used under optimized conditions, the $(R)$ allylation isomer was isolated in a similar $60 \%$ ee (entry 15 ). Switching to the saturated carbohelicenes derivative $(M)-1 \mathrm{~h}$ led to a slight improvement and the $(R)$ product was obtained in $66 \%$ ee (entry 16).

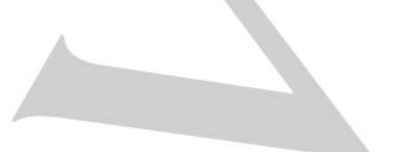

Table 1. Asymmetric Tsuji-Trost allylation in the presence of chiral helical phosphinites $(M)-1$.

\begin{tabular}{|c|c|c|c|c|c|c|c|}
\hline & $L^{*}$ & $x$ & y & $\begin{array}{l}\text { roduced } \\
P: P d \\
\text { ratio }\end{array}$ & T & Yield & $e e^{[a]}$ \\
\hline $1^{3}$ & $1 a$ & 0.5 & 0.25 & $2: 1$ & rt & $\begin{array}{c}60- \\
64 \% \%^{[b]}\end{array}$ & $\begin{array}{c}84-88 \% \\
(S)\end{array}$ \\
\hline $2^{3}$ & $1 a$ & 1 & 0.25 & $4: 1$ & $\mathrm{rt}$ & $100 \%$ [b] & $\begin{array}{c}82-86 \% \\
(S)\end{array}$ \\
\hline $3^{7}$ & $1 e$ & 1 & 0.5 & $1: 1$ & rt & $99 \%[c]$ & $\begin{array}{c}71-94 \% \\
\text { (S) }\end{array}$ \\
\hline $4^{8}$ & $1 f$ & 10 & 2.5 & $2: 1$ & $0{ }^{\circ} \mathrm{C}$ & $96 \%$ & $\begin{array}{c}84-90 \% \\
(S)\end{array}$ \\
\hline 5 & $1 \mathrm{~g}$ & 0 & 2.5 & $0: 1$ & $\mathrm{rt}$ & $0 \%$ & - \\
\hline 6 & $1 \mathrm{~g}$ & 5 & 2.5 & $2: 1$ & $\mathrm{rt}$ & $90-95 \%$ & $\begin{array}{c}25 \%(S) \\
\text { to } 16 \% \\
\quad(R)\end{array}$ \\
\hline 7 & $1 \mathrm{~g}$ & 10 & 2.5 & 4:1 & rt & $89 \%$ & $49 \%$ (S) \\
\hline 8 & $1 \mathrm{~g}$ & 5 & 4 & $1.2: 1$ & $\mathrm{rt}$ & $52 \%$ & $41 \%(R)$ \\
\hline 9 & $1 \mathrm{~g}$ & 5 & 5 & $1: 1$ & $\mathrm{rt}$ & $89 \%$ & $50 \%(R)$ \\
\hline 10 & $1 \mathrm{~g}$ & 5 & 6 & $0.8: 1$ & $\mathrm{rt}$ & $89 \%$ & $60 \%(R)$ \\
\hline 11 & $1 \mathrm{~g}$ & 5 & 8 & $0.6: 1$ & $\mathrm{rt}$ & $88 \%$ & $62 \%(R)$ \\
\hline 12 & $1 \mathrm{~g}$ & 5 & 10 & $0.5: 1$ & $\mathrm{rt}$ & $69 \%$ & $60 \%(R)$ \\
\hline 13 & $1 \mathrm{~g}$ & 5 & 8 & $0.6: 1$ & $0^{\circ} \mathrm{C}$ & $0 \%$ & - \\
\hline 14 & $1 \mathrm{~g}$ & 5 & 8 & $0.6: 1$ & $40^{\circ} \mathrm{C}$ & $93 \%$ & $52 \%(R)$ \\
\hline 15 & $1 \mathrm{i}$ & 5 & 8 & $0.6: 1$ & $\mathrm{rt}$ & $62 \%$ & $60 \%(R)$ \\
\hline 16 & 1h & 5 & 8 & $0.6: 1$ & rt & $63 \%$ & $66 \%(R)$ \\
\hline
\end{tabular}

[a] All results were homogenized for the use of $(M)$-ligand, for the sake of clarity, see reference 15. HPLC conditions: Chiralpak AD-H, hexanes/isopropanol 90:10, $1 \mathrm{ml} / \mathrm{min}, \lambda=254 \mathrm{~nm}$; [b] conversion; [c] $\mathrm{Cs}_{2} \mathrm{CO}_{3}$ was used as the base

It should be noted that the P:Pd ratio does not commonly influence the observed ee in Tsuji-Trost allylation, nor in the case of helical ligands as reported by Reetz and co-workers.[16] This ratio is often not even taken into account while studying new catalytic conditions, as two equivalents of "binding group" (here phosphorus atom) per palladium atom are required to generate a reactive palladium species. However, we can find in the literature a few reports featuring the crucial influence of the ligand-to-metal ratio by using specific ligands such as chiral phosphine oxazoline L1 and L3 or phosphorus-nitrogen-nitrogen ligand L2 (Figure 
4). ${ }^{[17]}$ Impressive improvements in the selectivity (from racemates to nearly optically pure products) with sometimes reversal of the selectivity are reported by modulating the ligand-to-palladium ratio and the authors generally evoked a change of the ligand coordination mode.[18]

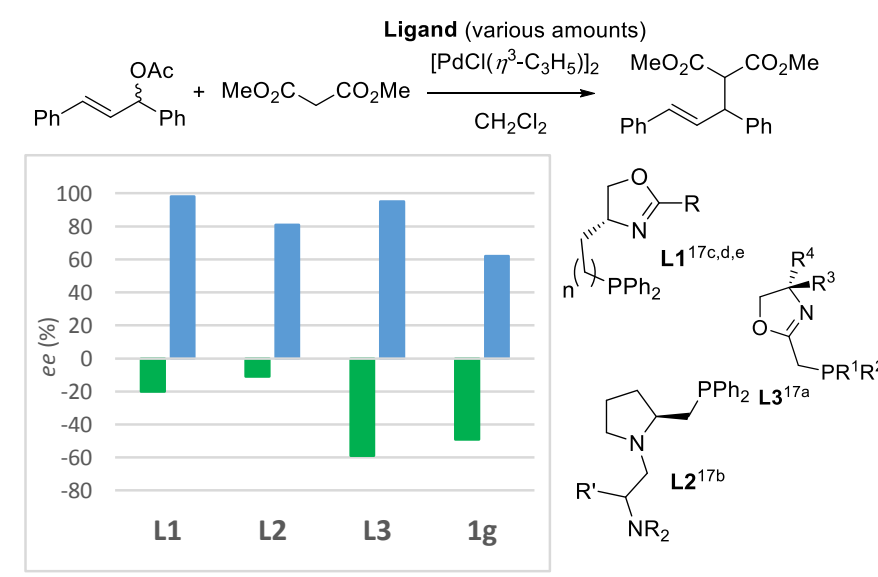

Figure 4. Ligands with crucial ligand-to-metal ratio effect in Tsuji-Trost allylation $^{[17]}$

\section{Metallic species study}

In order to clarify the evolution of the enantioselectivity we observed, we carried out ${ }^{31} \mathrm{P}$ NMR monitoring $\left(\mathrm{CD}_{2} \mathrm{Cl}_{2}, 162 \mathrm{MHz}\right.$, rt) of the metallic species in solution, by using a model palladium complex, $(\mathrm{MeCN})_{2} \mathrm{PdCl}_{2}$, and successive additions of bisphosphinite ligand $(M)-\mathbf{1 g}$. Figure 5 represents together the spectrum of the starting bisphosphinite ligand $(M)$-1g (Spectrum $\mathrm{S} 1, \delta=108.1 \mathrm{ppm}$ ) as well as the monitoring of the reaction by successive additions of ligand on palladium.

First, we added 0.25 equivalent of ligand $(M)-\mathbf{1 g}$ i.e. a ratio of phosphinite functions/palladium atom $=\mathrm{P}: \mathrm{Pd}=0.5: 1$. This ratio corresponds to that of the catalytic species which leads to the $(R)$ isomer with a $60 \%$ enantiomeric excess when $\left[\mathrm{Pd}\left(\eta-\mathrm{C}_{3} \mathrm{H}_{5}\right) \mathrm{Cl}\right]_{2}$ was used as a source of palladium (Table 1, entry 12). After $1 \mathrm{~h}$ at rt, full consumption of the ligand was observed to give species I whose chemical shift is $\delta=103.3 \mathrm{ppm}$ in ${ }^{31} \mathrm{P}$ NMR (spectrum S2). Another 0.25 equivalent of ligand was then added to the NMR tube, for a total of 0.5 equiv and a $P: P d$ ratio of $1: 1$. This ratio corresponds to that of the catalytic species which leads to isomer $(R)$ with an excess of $50 \%$ (Table 1, entry 9 ). After $1 \mathrm{~h}$ stirring, species I at $103.3 \mathrm{ppm}$ is still present and we observed the appearance of a second species II at $\delta=117.8 \mathrm{ppm}$ (spectrum S3). We then performed another addition of 0.5 equivalent of ligand, i.e. a total of 1 equiv and a $P: P d$ ratio $=2: 1$. This ratio corresponds to that of the catalytic identity which leads in turn to the $(S)$ and the $(R)$ isomer with low enantiomeric excesses (Table 1 , entry 6$)$. After $1 \mathrm{~h}$, we noted the total disappearance of the first species I and the unique presence of species II (spectrum S4). This second species revealed highly sensitive to air as it quickly decomposed to the secondary phosphine oxide $(\delta=77.9 \mathrm{ppm})$ with concomitant helixol $\mathbf{7 g}$ formation. Finally, one additional equivalent of ligand $\mathbf{1 g}$ was added to species II to reach the $4: 1$ $\mathrm{P}: \mathrm{Pd}$ ratio corresponding to that of the catalytic species yielding the $(S)$-enantiomer in $49 \%$ ee (Table 1, entry 7 ). Appearance of a third species was observed. This new species is dissymmetric as the two phosphinites groups splitted in two singlets at $\delta=113.9$
(1P), 107.1 (1P) (Spectrum S5). Unfortunately, it also revealed highly unstable as it quickly decomposed in the NMR tube.

This experiment suggests that there can be at least three different catalytic species in solution according to the amount of ligand.

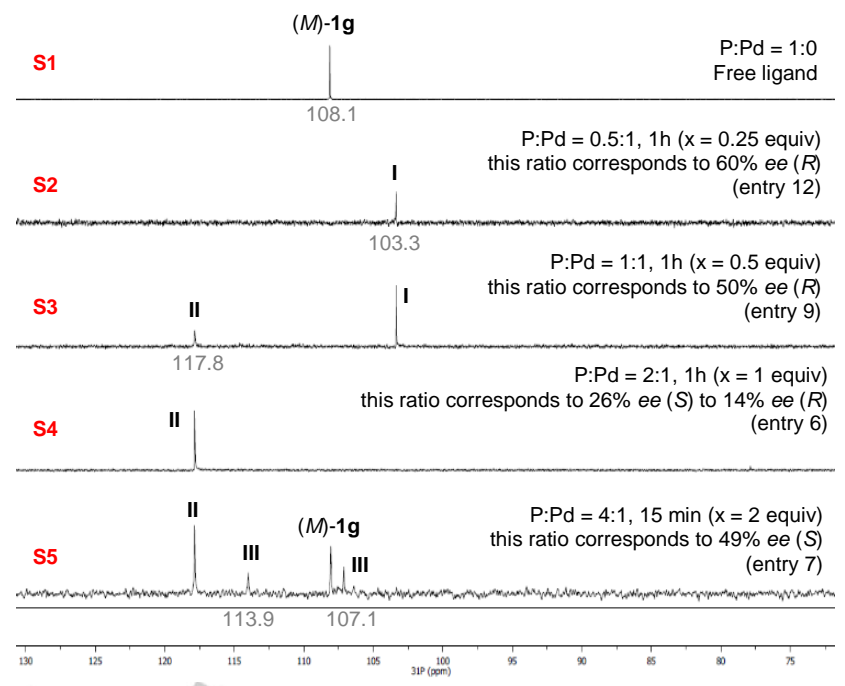

Figure 5. ${ }^{31} \mathrm{P}$ NMR monitoring of the metallic species in model $\mathrm{PdCl}_{2}(\mathrm{MeCN})_{2}$ system

DFT calculations shed light on a possible structure for the $1: 1 \mathrm{P}$ : Pd species I. Indeed, similarly to what was observed by Usui, Suemune and co-workers for the 5-phosphane helical ligand $(X$ ray crystallography),[7] Species I may rely on a palladium-arene stacking (Calculated $\mathrm{Pd} \cdots$ arene distance $=2.806 \AA$ and $3.108 \AA$, Figure 6). Transposed to the real catalyst $\left[\left(\eta-\mathrm{C}_{3} \mathrm{H}_{5}\right) \mathrm{PdCl}\right]_{2}$, the allyl environment would be strongly asymmetric that can explain the $60 \%$ ee observed (Figure 6).
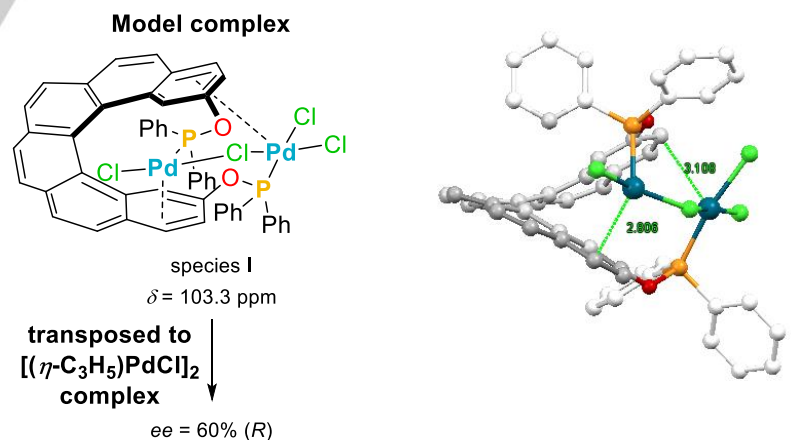

Figure 6: suggested structure for model species $(M)-I(P d \cdots C=2.806 \AA$ and $3.108 \AA$ ) (DFT).

To elucidate the stereoselectivity observed with this $\mathrm{P}: \mathrm{Pd}$ ratio, DFT calculations preceded by DFTB (namely with $x t b$ ) conformational search were performed for geometry optimization of ( $\pi$-allyl)palladium intermediates ((M)-I-syn,syn, (M)-I-anti,anti and (M)-I-syn,anti), the (syn,syn), (syn,anti) and (anti,anti) characterizing the approach and the conformation of the allyl part.[19] Figure 7 shows their calculated relative energies of formation, with (M)-I-syn,anti being the most stable based on these calculations. Indeed, the (M)-I-syn,syn (endo approach of the allyl partner) and (M)-I-anti,anti (exo approach) intermediates suffer from steric repulsion between the helicene backbone and the allylic groups, leading to allylic chain isomerization. Assuming 
that nucleophilic attack on the allyl complex takes place at the $\mathrm{C} 1$ allylic carbon atom due to the larger trans effect of phosphorus,[20] (M)-I-syn,anti affords the product with $(R)$ configuration. This is clearly reflected in the longer $\mathrm{Pd}-\mathrm{C} 1$ bond

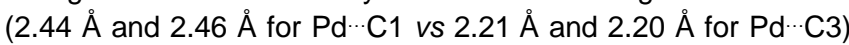
and the higher computed Hirschfeld-charge of the $\mathrm{C} 1$ position (0.02e at C1 vs $0.001 \mathrm{e}^{-}$at C3).
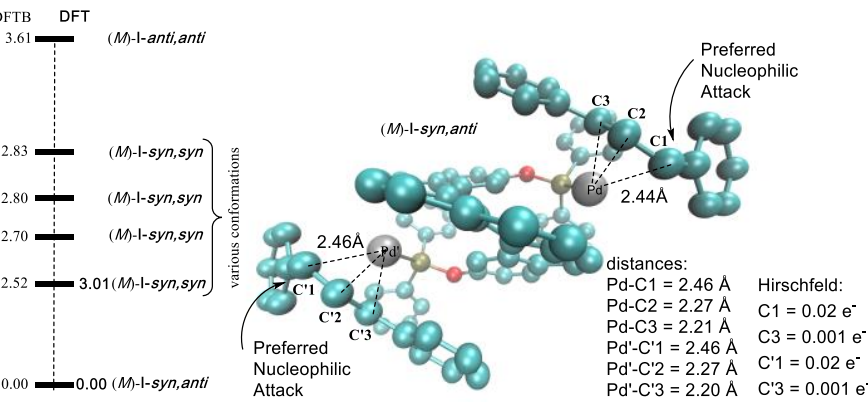

Figure 7: Calculated energies of formation (DFT) of the (m-ally)palladium intermediates with $(M)-1(P: P d=1: 1)$ and structure of the more stable one (M)-I-syn,anti

More information arose from crystallization of S3 mixture by slow evaporation of deuterated dichloromethane (Figure 8). X-ray diffraction disclosed a 2:1 P:Pd complex, that ratio matches species II. This species is a dimeric bimetallic species. The average P---P distance is $8.44(4) \AA$, and both helices disclose a rather short, average 3.06(15) $\AA$, inner pitch elevation (C1---C16). The interplanar angles of the two terminal rings are $55.2(4)^{\circ}$ and $53.2(4)^{\circ}$. Both palladiums adopt a planar square geometry with P-Pd-P angles of $99.9(1)^{\circ}$ and $100.4(1)^{\circ}$.

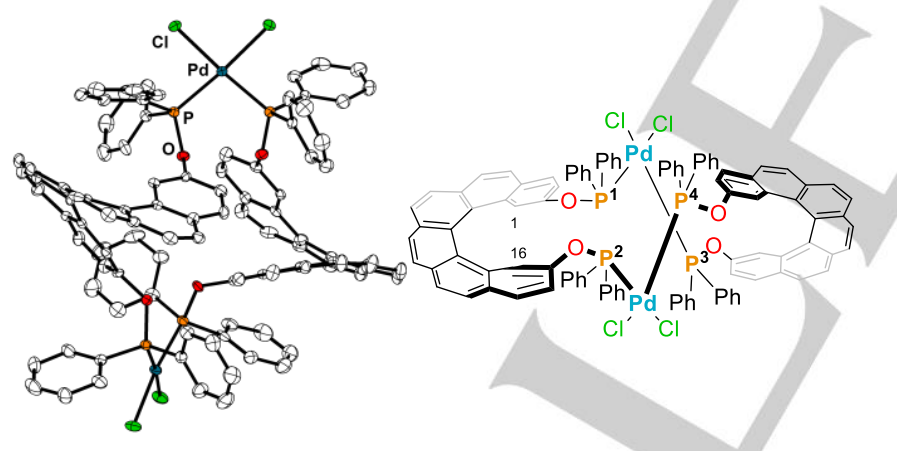

Figure 8. X-ray of model species of a 2:1 P:Pd complex, matching $(P, P)$-II ratio, with thermal ellipsoids at $30 \%$ probability. Hydrogen atoms and solvent omitted for clarity.

This bismetallic complex revealed nearly no steric hindrance at either of the chlorine atom. This finding would easily explain the non-reproducible and very low ee obtained when a $\mathrm{P}: \mathrm{Pd}=2: 1$ ratio is used in catalysis (Table 1 , entry 6 ). DFT calculations of the real reactive intermediates confirmed this finding as both $\mathrm{C} 1$ and C3 carbons have similar charges (Hirschfeld charges) and similar $\mathrm{Pd}-\mathrm{C}$ distances in all conformers, whatever the endo or exo approach of the allyl partner, or its syn-anti conformational switch (the most stable intermediate (M)-I-syn,syn is represented in Figure 9) (see SI for details on the other intermediates). ${ }^{[19]}$ Such an energy profile should in theory lead to racemic products.
However, due to experimental uncertainties, a slight defect or excess of ligand tips the balance one way or the other.

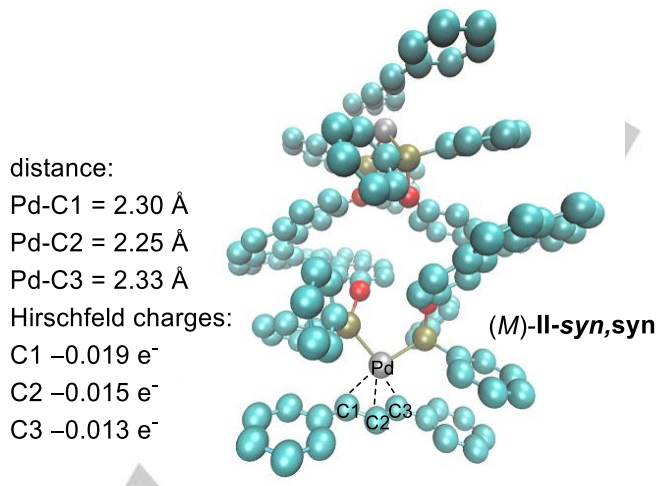

Figure 9: Calculated structure (DFT) for (M)-II-syn,syn, the most stable ( $\pi-$ ally)palladium reaction intermediate with $(M)-1(P: P d=2: 1)$.

Finally, the 4:1 P:Pd species III was investigated. In the presence of 2 equivalents of ligand per palladium atom, we can suggest the mono-ligandation of the bisphoshinite, with two unequivalent phosphinite moieties per ligand. Such a species would be structurally similar to the one probably formed in Tsujihara's and Kawano's report with monodental phosphinite $1 f(P: P d=2: 1)$ and would explain the formation of the same $(S)$ enantiomer they obtained albeit with erosion of the stereoselectivity, as the phosphinite function is anchored in position 2, so further than in Tsujihara's and Kawano's report (1-phosphinite[6]helicene, 89\% ee (S)).[8] Once again, DFT calculations confirmed the enantioselection with a preferred attack on $\mathrm{C} 1$ leading to $(S)$ enantiomer. Interestingly, we found a sandwich conformer lying just above the most stable one (M)-III-syn,syn, in which $\pi$-stacking between the allylic moiety and the phosphinite makes the electrophilic carbons inaccessible (Figure 10).

(a) Model complex: Species III (DFT)

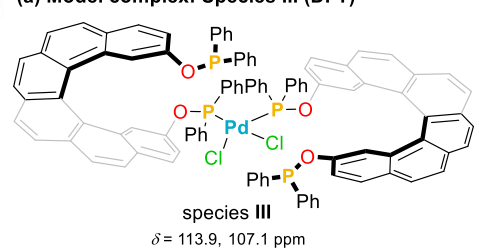

(b) $\left[\left(\eta-\mathrm{C}_{3} \mathrm{H}_{5}\right) \mathrm{PdCl}\right]_{2}$ (DFT) ee $=49 \%(S)$
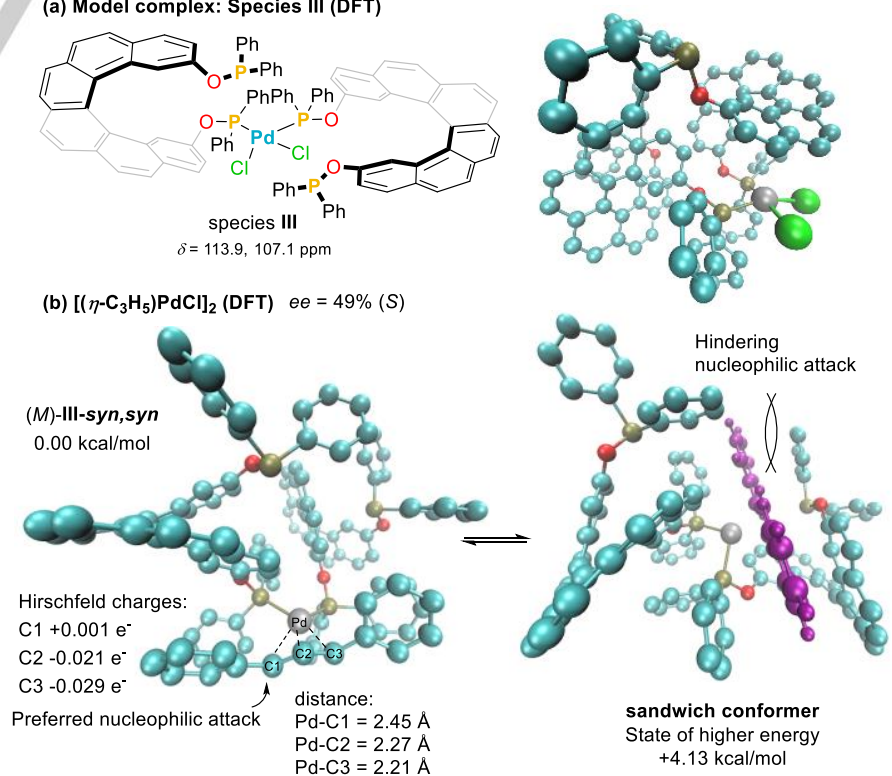

Figure 10: (a) Suggested structure for model species (M)-III (DFT); (b) Calculated structure (DFT) of the most stable ( $\pi$-ally)palladium intermediate (M)-III-syn,syn ( $\mathrm{P}: \mathrm{Pd}=4: 1)$ (left) and of the one of higher energy (right) 


\section{Conclusion}

The study of chiral 2,15-bisphosphinite[6]helicene as a ligand in asymmetric palladium-catalyzed Tsuji-Trost allylic alkylation led to remarkable results in term of switch of stereoselectivity. Unlike the related results disclosed with 1-phosphinite[6]helicene, 1-phosphane[5]helicene or 2,15-bisphosphine[6]helicene, the ligand-to-metal ratio revealed critical with this peculiar ligand. Indeed, we have shown that this ratio had a dramatical effect on the stereoselectivity when using chiral 2,15-bisphosphinites [6] helicene ligand. In fact, we showed that the $(R)$ and $(S)$ isomers can be selectively formed as a direct function of the amount of ligand introduced by moving from $4: 1$ to $1: 1$ phosphore-topalladium ratio. Thanks to ${ }^{31} \mathrm{P}$ NMR study on a model palladium complex, X-ray analysis of a 2:1 P:Pd adduct and DFT calculations, we suggested three different organometallic structures in 1:1, 2:1 and 4:1 P:Pd ratios. DFT calculations on these complexes matched the enantioselectivity observed in reaction conditions. This study enlights the key importance of ligand-to-metal ratio screening while evaluating new ligands. Studies are undergoing in our laboratory to crystallizing the two other organometallic species to confirm their structures.

\section{Experimental Section}

To a mixture of $\left[\mathrm{Pd}\left(\eta^{3}-\mathrm{C}_{3} \mathrm{H}_{5}\right) \mathrm{Cl}\right]_{2}$, phosphinite ligand , and LiOAc (1.8 mg, $0.027 \mathrm{mmol}, 10 \mathrm{~mol} \%)$ in $\mathrm{CH}_{2} \mathrm{Cl}_{2}(0.5 \mathrm{~mL})$ was added a solution of $1,3-$ diphenyl-2-propenyl acetate (52.3 mg, $0.20 \mathrm{mmol}, 1$ equiv) in $\mathrm{CH}_{2} \mathrm{Cl}_{2}$ (1.5 $\mathrm{mL}$ ) at room temperature under $\mathrm{Ar}$ atmosphere. After $30 \mathrm{~min}$, dimethyl malonate (70 $\mu \mathrm{L}, \quad 0.60 \mathrm{mmol}, \quad 3.0$ equiv) and $\mathrm{N}, \mathrm{O}$ bis(trimethylsilyl)acetamide (BSA) $(154 \mu \mathrm{L}, 0.60 \mathrm{mmol}, 3.0$ equiv) were successively added at rt. After $24 \mathrm{~h}$, the reaction mixture was diluted quenched with water. The separated aqueous layer was extracted with $\mathrm{CH}_{2} \mathrm{Cl}_{2}$, and the combined organic extracts were washed with brine, dried over $\mathrm{MgSO}_{4}$, filtered and concentrated in vacuo. Purification by flash column chromatography on silica gel (PE/EtOAc 95/5) afforded the desired product as a white solid.

\section{Acknowledgements}

This work was supported by the CNRS, Sorbonne Université, IUF and Agence Nationale de la Recherche (ANR-13-JS07-0013HELCATS). We warmly thank Siham El Aani, Corentin Fagnan, Tiffany Gosse, Delphine Haddad, Soizic Queric and Shiwen Zheng who worked on starting material synthesis.

Keywords: helicene $\cdot$ phosphinite $\cdot$ homogeneous catalysis $•$ chirality $\cdot$ Tsuji-Trost allylation

[1] For recent reviews and book, see: (a) K. Dhbaibi, L. Favereau, J. Crassous, Chem. Rev. 2019, 119, 14, 8846-8953. (b) C.-F. Chen, Y. Shen, Helicene Chemistry. Springer-Verlag Berlin Heidelberg, 2017; (c) N. Saleh, C. Shen, J. Crassous. Chem. Sci. 2014, 5, 3680-3694; (d) P. Aillard, A. Voituriez, A. Marinetti, Dalton Trans. 2014, 43, 15263-15278; (e) M. J. Narcis, N. Takenaka, Eur. J. Org. Chem. 2014, 21-34; (f) Y. Shen, C.-F. Chen, Chem. Rev. 2012, 112, 1463-1535; (g) M. Gingras, Chem. Soc. Rev. 2013, 42, 1051-1095.

[2] M. T. Reetz, E. W. Beuttenmüller, R. Goddard, Tetrahedron Lett. 1997, 38, 3211-3214; b) A. Terfort, H. Görls, H. Brunner, Synthesis 1997, 7986.
[3] M. T. Reetz, S. Sostmann, J. Organomet Chem 2000, 603, 105-109

[4] M. Monteforte, S. Cauteruccio, S. Maiorana, T. Benincori, A.Forni, L. Raimondi, C. Graiff, A. Tiripicchio, G. R. Stephenson, E. Licandro, Eur. J. Org. Chem. 2011, 5649-5658

[5] Z. Krausová, P. Sehnal, B. P. Bondzic, S. Chercheja, P. Eilbracht, I. G. Stará, D. Šaman, I. Starý, Eur. J. Org. Chem. 2011, 3849-3857.

[6] K. Yavari, P. Aillard, Y. Zhang, F. Nuter, P. Retailleau, A. Voituriez, A Marinetti, Angew. Chem. Int. Ed. 2014, 53, 861-865; (b) K. Yavari, P. Retailleau, A. Voituriez, A. Marinetti, Chem. Eur. J. 2013, 19, 9939-9947; (c) P. Aillard, A. Voituriez, D. Dova, S. Cauteruccio, E. Licandro, A. Marinetti, Chem. Eur. J. 2014, 20, 12373-12376; (d) P. Aillard, P. Retailleau, A. Voituriez, A. Marinetti, Chem. Eur. J. 2015, 21, 1198911993 ; (e) Chem Commun. 2016, 52, 10984 - 10987.

[7] K. Yamamoto, T. Shimizu, K. Igawa, K. Tomooka, G. Hirai, H. Suemune, K. Usui, Scientific Reports 2016, 6, 36211.

[8] T. Tsujihara, N. I. Nozaki, T. Takehara, D. Y. Zhou, T. Suzuki, T. Kawano, Eur. J. Org. Chem. 2016, 29, 4948.

[9] C. Medena, F. Calogero, Q. Lemoine, C. Aubert, E. Derat, L. Fensterbank, G. Gontard, O. Khaled, N. Vanthuyne, J. Moussa, C. Ollivier, M. Petit, M. Barbazanges, Eur. J. Org. Chem. 2019, 2129.

[10] F. Teplý, I. G. Stará, I. Starý, A. Kollárovič, D. Luštinec, Z. Krausová, D. Šaman, P. Fiedler, Eur. J. Org. Chem. 2007, 4244-4250.

[11] Cleavage of the benzylic ethers can be prevented by changing the protecting group, from methoxy to silylated ether, see Supporting information for more details.

[12] Preparative Chiral HPLC, see supporting information

[13] O. Pàmies, J. Margalef; S. Cañellas, J. James, E. Judge, P. J. Guiry, C. Moberg, J.-E. Bäckvall, A. Pfaltz, M. A. Pericàs, M. Diéguez, Chem. Rev. 2021, 121, 4373-4505.

[14] G. Poli, G. Prestat, F. Liron, C. Kammerer-Pentier, Top. Organomet Chem. 2012, 38, 1.

[15] For the sake of clarity, all results were homogenized for the use of a $(M)$-helix, i.e. if $(P)$-helix was in fact used, we inversed the enantiomer obtained.

[16] In case of 2,15-bisphosphane-[6]helicene, the authors state that "the ligand-metal ratio has no significant effect on enantioselectivity", see reference 3

[17] For the examples reporting a, important influence of the L/Pd ratio on the enantioselectivity in asymmetric Tsuji-Trost allylation reactions, see: (a) H. Danjo, M. Higuchi, M. Yada, T. Imamoto, Tetrahedron Lett. 2004, 45, 603-606; (b) X. Cheng, K. K. Hii, Tetrahedron: Asymmetry 2003, 14, 2045; (c) D.-R. Hou, J. H. Reibenspies, K. Burgess, J. Org. Chem. 2001, 66, 206; (d) A. M. Porte, J. Reibenspies, K. Burgess, J. Am. Chem. Soc. 1998, 120, 9180; (e) K. Burgess, A. M. Porte, Tetrahedron: Asymmetry, 1998, 9, 2465.

[18] For examples of other catalytic transformations in which the ligand-tometal ratio is critical see: $\mathrm{Pd}$ : (a) J. Li, S.-S. Wang, P.J. Xia, Q.-L. Zhao, J.-A. Xiao, H.-Y. Xiang, X.-Q. Chen, H. Yang Eur. J. Org. Chem. 2017 6961-6965; (b) S. Wang, J. Xiao, J. Li, H. Xiang, C. Wang, X. Chen, R G. Carter and H. Yang, Chem. Commun., 2017, 53, 4441; (c) E Bélanger, C. Houzé , N. Guimond, K. Cantin, J.-F. Paquin, Chem. Commun. 2008, 3251-3253; Other metals: (d) Peng, Z. Shao and A. S. C. Chan, Tetrahedron: Asymmetry, 2010, 21, 465-468; (e) M. I. Burguete, M. Collado, J. Escorihuela S. V. Luis, Angew. Chem., Int. Ed., 2007, 46, 9002-9005; (f) Z. Shao, J. Wang, K. Ding, A. S. C. Chan, Adv. Synth. Catal. 2007, 349, 2375-2379. (g) R. Rasappan, M. Hager, A. Gissibl, O. Reiser, Org. Lett., 2006, 8, 6099; (h) G. C. Lloyd-Jones, C. P. Butts, Tetrahedron, 1998, 54, 901

[19] DFT calculation was performed with Turbomole v6.5 at the B3LYP-D3 level with the def2-SV(P) basis set, see supporting information

[20] R. N. Constantine, N. Kim, R. C. Bunt, Org. Lett. 2003, 5, 2279-2282. 


\section{Entry for the Table of Contents}

Insert graphic for Table of Contents here. ((Please ensure your graphic is in one of following formats))

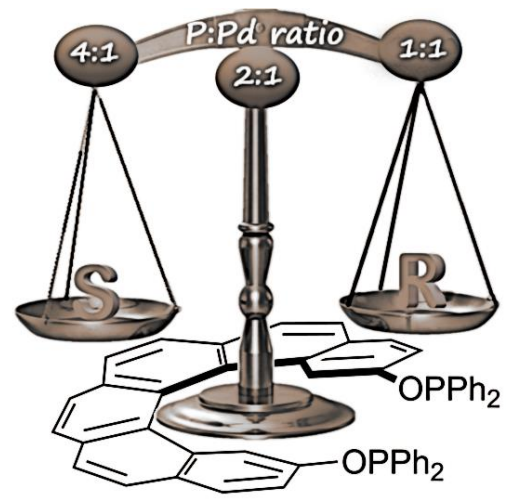

Insert text for Table of Contents here.

A remarkable effect of the ligand to metal ratio in the palladium-catalyzed Tsuji-Trost allylation is revealed here. By changing the amount of chiral bisphosphinite[6] helicene ligand in the catalytic system, $(R)$ and $(S)$ isomeric products were selectively obtained. ${ }^{31} \mathrm{P}$ NMR, $\mathrm{X}$-ray and DFT calculation were used to shed light on this reaction.

Institute and/or researcher Twitter usernames: ((optional)) 
Click here to access/download Supporting Information SI_BARBAZANGES.docx 